\title{
Short-Term Depression in Thalamocortical Synapses of Cat Primary Visual Cortex
}

\author{
C. Elizabeth Boudreau and David Ferster \\ Department of Neurobiology and Physiology, Northwestern University, Evanston, Illinois 60208
}

\begin{abstract}
Neurons in primary visual cortex exhibit several nonlinearities in their responses to visual stimuli, including response decrements to repeated stimuli, contrast-dependent phase advance, contrast saturation, and cross-orientation suppression. Thalamocortical synaptic depression has been implicated in these phenomena but has not been examined directly in visual cortex in vivo. We assessed depression of visual thalamocortical synapses in vivo using $20-100 \mathrm{~Hz}$ trains of electrical stimuli delivered to the LGN. Cortical cells receiving direct input from the LGN, identified by short latency and low jitter of LGN-evoked PSPs, showed moderate reductions in PSP amplitude during the fastest trains. Cells receiving indirect input from the thalamus via other cortical excitatory neurons show a marked reduction in PSP amplitude during a train, which could be explained either by synaptic depression in corticocortical synapses or by an inhibition-mediated suppression of the firing of their afferents. Reducing spontaneous activity in the LGN (by retinal blockade) unmasked additional depression at the thalamocortical synapse but only for the first stimulus in the train. That is, the first PSP was increased in amplitude relative to the unblocked condition, but subsequent responses were essentially unchanged. Thus, the synapses are maintained at significant levels of depression by spontaneous activity. These findings constrain the role that thalamocortical depression can play in shaping cortical responses to visual stimuli.
\end{abstract}

Key words: LGN; visual cortex; V1; synaptic depression; cat; intracellular recording; in vivo

\section{Introduction}

Between the LGN and visual cortex, there is a unique, qualitative change in the representation of stimuli. The response properties arising from this transformation-sensitivity to orientation, motion, size, and depth — define our understanding of cortical visual processing at the single-cell level. Several cellular mechanisms contribute to the transformation of geniculate relay cell output into cortical cell output, including the integration of excitatory and inhibitory inputs, threshold (Carandini and Ferster, 2000; Volgushev et al., 2002), and activity-dependent hyperpolarization (Carandini and Ferster, 1997; Sanchez-Vives et al., 2000). Existing models based on these mechanisms can explain many response properties of cortical neurons.

Some cortical response properties, however, seemingly cannot be explained through network integration and intrinsic cellular mechanisms alone. Several authors have proposed that short-term synaptic depression (Abbott et al., 1997; Tsodyks and Markram, 1997) might underlie these phenomena, which include cross-orientation suppression (Lauritzen et al., 2001; Carandini et al., 2002; Freeman et al., 2002), size tuning (Ozeki et al., 2004), and adaptation to brief, successive visual stimuli (Nelson, 1991a,b,c; Muller et al., 1999).

Received Dec. 16, 2004; revised June 16, 2005; accepted June 17, 2005.

This work was supported by National Institutes of Health Grant R01EY04726. We thank Chinfei Chen, Indira Raman, Nicholas Priebe, lan Finn, and Hirofumi Ozeki for insightful comments during the preparation of this manuscript.

Correspondence should be addressed to Dr. C. E. Boudreau, Department of Neurobiology and Physiology, 2205 Tech Drive, Hogan 2-160, Evanston, IL 60208. E-mail: bethb@northwestern.edu.

DOI:10.1523/JNEUROSCI.1445-05.2005

Copyright $\odot 2005$ Society for Neuroscience $\quad$ 0270-6474/05/257179-12\$15.00/0
Models of the cortical circuit have also shown that synaptic depression at thalamocortical synapses or corticocortical synapses could contribute to several other cortical properties. (1) Chance et al. (1998) showed that depressing synapses can account for frequency-dependent shifts in the temporal phase of grating responses (Dean and Tolhurst, 1986; Reid et al., 1991). (2) Depressing synapses might underlie response decrements at high temporal frequencies, although LGN relay cells respond robustly to such stimuli (Kayser et al., 2001). (3) Synaptic depression could contribute to direction selectivity by creating different visual latencies in different parts of cortical receptive fields (Adelson and Bergen, 1985; Chance et al., 1998; Buchs and Senn, 2002).

Synaptic depression has been observed at the thalamocortical synapse of somatosensory cortex in vitro (Gibson et al., 1999; Gil et al., 1999; Beierlein and Connors, 2002) and in vivo in the barrel cortex of rat (Castro-Alamancos, 2002; Chung et al., 2002) and rabbit (Swadlow et al., 2002). In the visual system, synaptic depression has been found at thalamocortical synapses in the cat in vitro (Stratford et al., 1996; Bannister et al., 2002). In whole animals, however, evidence for thalamocortical depression in the visual system is controversial. Whereas field potential recordings suggest substantial geniculocortical depression in the rat (Jia et al., 2004), extracellular studies in the cat found facilitation of spike efficacy in response to LGN spikes elicited at short intervals (Usrey et al., 2000). Additionally, responses to electrical stimulation of the LGN are facilitated during and after the presentation of a visual stimulus (Kara et al., 2002).

We have recorded responses evoked in vivo by trains of electrical stimuli to the LGN. Thalamically driven PSPs depressed only moderately, even during high-frequency $(100 \mathrm{~Hz})$ trains. 
More depression appeared in the response to the second stimulus in a train when retinal inactivation reduced spontaneous activity in the LGN, suggesting that thalamocortical synapses are tonically depressed by spontaneous activity, limiting the impact of additional evoked activity on synaptic efficacy.

\section{Materials and Methods}

Animal preparation. Adult cats weighing $2-3 \mathrm{~kg}$ were used for acute experiments. Anesthesia was induced with ketamine hydrochloride (30 $\mathrm{mg} / \mathrm{kg}$ ) and acepromazine maleate $(0.3 \mathrm{mg} / \mathrm{kg})$ injected intramuscularly. A cannula was inserted into the femoral vein, through which sodium thiopental was then infused at a rate of $20-30 \mathrm{mg} \cdot \mathrm{kg}^{-1} \cdot \mathrm{hr}^{-1}$ during the remaining surgical procedures and $3-5 \mathrm{mg} \cdot \mathrm{kg}^{-1} \cdot \mathrm{hr}^{-1}$ during the remainder of the experiment. A second femoral cannula was inserted for delivery of the paralytic, either vecuronium bromide $(1.5 \mathrm{mg} / \mathrm{kg}$ initial dose, $0.2 \mathrm{mg} \cdot \mathrm{kg}^{-1} \cdot \mathrm{hr}^{-1}$ infusion rate) or gallamine triethiodide (10 $\mathrm{mg} / \mathrm{kg}$ initial dose, $10 \mathrm{mg} \cdot \mathrm{kg}^{-1} \cdot \mathrm{hr}^{-1}$ infusion rate), to minimize eye movements during recording. To ensure proper depth of anesthesia during surgery, paralytic was not administered until after the completion of all surgical procedures except the pneumothorax. After the beginning of paralytic administration, animals were artificially respirated through a tracheal cannula, inserted during surgery, to maintain an end-tidal $\mathrm{CO}_{2}$ of $3.5-4.0 \%$. To minimize movement of the brain attributable to respirations, the thoracic vertebrae were suspended from the stereotaxic apparatus, and a bilateral pneumothorax was performed. Body temperature was maintained at $38.3^{\circ} \mathrm{C}$ with a feedback-controlled heating lamp. After paralysis, depth of anesthesia was assessed by measuring heart rate and EEG, which was recorded through two cranial screws.

Electrical stimulation. Electrical stimuli were delivered through etched, lacquer-coated tungsten wire electrodes with $\sim 150 \mu \mathrm{m}$ exposed tips. Stimuli were electrode negative and $200 \mu$ s in duration. LGN electrodes were placed in layer A of the nucleus, identified by depth and contralateral eye specificity of responses recorded through the electrode during initial placement. The electrode was placed within the retinotopic map so that the receptive field of multiunit activity recorded through the stimulating electrode was within $1^{\circ}$ of the receptive fields of recorded cortical neurons. Negative-going field potentials at the cortical recording site could be reliably evoked by LGN stimulation at amplitudes of $130-250$ $\mu \mathrm{A}$. Measurements of response amplitude and latency were made only on the early components of the responses ( $<6 \mathrm{~ms}$ ), because later components $(>10 \mathrm{~ms})$ can include augmenting input from the antidromically activated corticogeniculate axons (Ferster and Lindström, 1985). Blocks of 16 trains of 5-10 LGN stimuli were delivered at 20,50, or 100 $\mathrm{Hz}$ separated by a $1.75 \mathrm{~s}$ intertrain interval. Blocks were separated by 5-500 s.

Cortical stimulating electrodes were placed at a depth of $250-350 \mu \mathrm{m}$ and within $500 \mu \mathrm{m}$ of the cortical recording site. Cortical stimulation amplitudes ranged from 200 to $500 \mu \mathrm{A}$.

Intracellular recording. Recordings of membrane potential were obtained with both conventional sharp and whole-cell patch microelectrodes; conductance measurements were made only from whole-cell patch recordings. Sharp microelectrodes were filled with $2 \mathrm{M}$ potassium acetate (resistance of 30-110 M $\Omega$ ). Patch electrodes were filled with internal solution containing the following (in mM): $130 \mathrm{~K}^{+}$-gluconate, 2 $\mathrm{MgCl}_{2}$, 5 HEPES, 1.1 EGTA, $0.1 \mathrm{CaCl}_{2}$, and $4 \mathrm{Mg}^{2+}$-ATP. The solution was buffered to $\mathrm{pH} 7.3$ and adjusted to 285 mOsm. Patch electrode resistances were 5-15 M $\Omega$. Seal resistances were $>1 \mathrm{G} \Omega$, and access resistances after whole-cell configuration was achieved were 50-200 $\mathrm{M} \Omega$. Recordings with patch electrodes in which adequate seals or access resistances could not be achieved were treated as sharp recordings. Recordings were made in area 17 , within $5^{\circ}$ of the area centralis (HorsleyClark coordinates $1-3 \mathrm{~mm}$ lateral and $4-9 \mathrm{~mm}$ posterior). Exposed cortex was covered with warm agar ( $3 \%$ in $0.9 \%$ saline) during recording to prevent drying and minimize pulsations. Membrane potentials were recorded with an Axoclamp-2A amplifier (Axon Instruments, Union City, $\mathrm{CA}$ ) in current-clamp mode and digitized at $10 \mathrm{kHz}$ after low-pass filtering.

Latency determination. PSP latencies were determined by an automatic procedure. Averaged, normalized traces were fit with a sigmoidal function, $R=R_{\max } \times t^{n} /\left(t_{50}^{n}+t^{n}\right)+b$, and latency was taken to be the time of the peak of the second derivative of the function. Manual and automatic procedures yielded similar multimodal distributions of response latencies (see Fig. 3B). The division between putative monosynaptic and polysynaptic cells was chosen based on the shape of the distribution of measured latencies, as well as on previous studies using similar methods (Ferster and Lindström, 1983; Chung and Ferster, 1998).

Quantification of response amplitude. Responses to individual stimuli in each train were often superimposed on slow trends in membrane potential that developed over the course of the train. Whether the slow trend was depolarizing or hyperpolarizing depended on whether the shock-evoked EPSPs were of large enough amplitude and long enough duration to summate and thereby outweigh the long-lasting IPSP. Slow trends in either the hyperpolarizing or depolarizing direction occurred with equal likelihood in both monosynaptic and polysynaptic cells.

To facilitate the measurement of the incremental amplitude of individual responses, slow trends were first fit by interpolating between the membrane potential values recorded just before each shock (low-pass interpolation with a symmetric finite impulse response filter; Matlab; MathWorks, Natick MA). The fit was then subtracted from the original traces. The amplitude of the response to the first stimulus was measured at $90 \%$ of the peak, relative to baseline (the mean membrane potential measured between 0.7 and $1.2 \mathrm{~ms}$ after the stimulus onset). The amplitudes of later responses in the train were measured at the same time relative to the stimulus as the first response. Many cells showed incremental or augmenting responses (Ferster and Lindström, 1985), in which later components of the PSP grew larger with repeated stimulation. Augmenting responses are mediated at least in part by intracortical collaterals of antidromically activated corticogeniculate cells (Ferster and Lindström, 1985), and, because their latencies are longer than monosynaptic excitation from thalamic relay neurons, we excluded these late potentials from our analyses.

Extracellular recordings. Single-unit recordings in the LGN (see Fig. $9 A, B$ ) were made with glass-coated (Ainsworth et al., 1977) or lacquercoated tungsten electrodes. Extracellular signals were digitized at $15 \mathrm{kHz}$ and stored to disk. Units were isolated on-line with a dual-window discriminator (Bak Electronics, Mt. Airy, MD) and confirmed offline.

Conductance measurements. Whole-cell patch recordings in vivo typically have much higher access resistances (the resistance of the electrode after break-in) than in vitro recordings. To compensate for this resistance and therefore allow accurate estimation of the input resistance in our calculations of conductance, we balanced the bridge off-line. A series of current steps was injected periodically during the course of each recording and then fitted with the predictions of a model of the electrode and cell membrane as resistor-capacitor circuits in series (Anderson et al., 2000). The median estimated electrode time constant was $1.97 \pm 0.22 \mathrm{~ms}$ $(n=13)$.

To estimate conductance changes during electrical stimulation, membrane voltage responses to identical stimuli were recorded at several levels of constant current injection. The relationship between conductance and voltage at each current can be expressed as the following membrane equation: $C_{m} \times d V_{m} / d t=-\left[\Delta g_{i} \times\left(V_{m}-V_{\text {revi }}\right)+\Delta g_{e} \times\left(V_{m}-V_{\text {reve }}\right)+\right.$ $\left.g_{r} \times\left(V_{m}-V_{\text {rest }}\right)\right]+I_{\text {inj; }}$, where $g_{r}$ (which has a reversal potential at $\left.V_{\text {rest }}\right)$ comprises the resting excitatory and inhibitory synaptic conductances and other nonsynaptic conductances; it is assumed to be constant and equal to $1 / R_{m} \cdot g_{e}(t)$ and $g_{i}(t)$ are time varying and express the stimulusevoked changes in excitatory and inhibitory conductance relative to rest. Negative values indicate that a particular conductance has fallen below the resting value. $g_{e}(t)$ is assumed to reverse at $0 \mathrm{mV} ; g_{i}(t)$ is assumed to reverse at $-80 \mathrm{mV}$. The latter value is taken from in vitro measurements of the reversal potential of cortical IPSCs (Anderson et al., 2000; Shu et al., 2003). This reversal potential is meant to reflect a combination of $\mathrm{GABA}_{\mathrm{A}}$ - and $\mathrm{GABA}_{\mathrm{B}}$-mediated inhibition that is likely evoked by LGN stimulation. Changing the reversal potential for inhibition by $\pm 5 \mathrm{mV}$ scales the relative sizes of excitation and inhibition but does not qualitatively change the results.

The system of linear equations that resulted from our recordings of $V_{m}$ at several values of $I_{\text {inj }}$ was fit to find the best estimates of $g_{e}(t)$ and $g_{i}(t)$ (in 

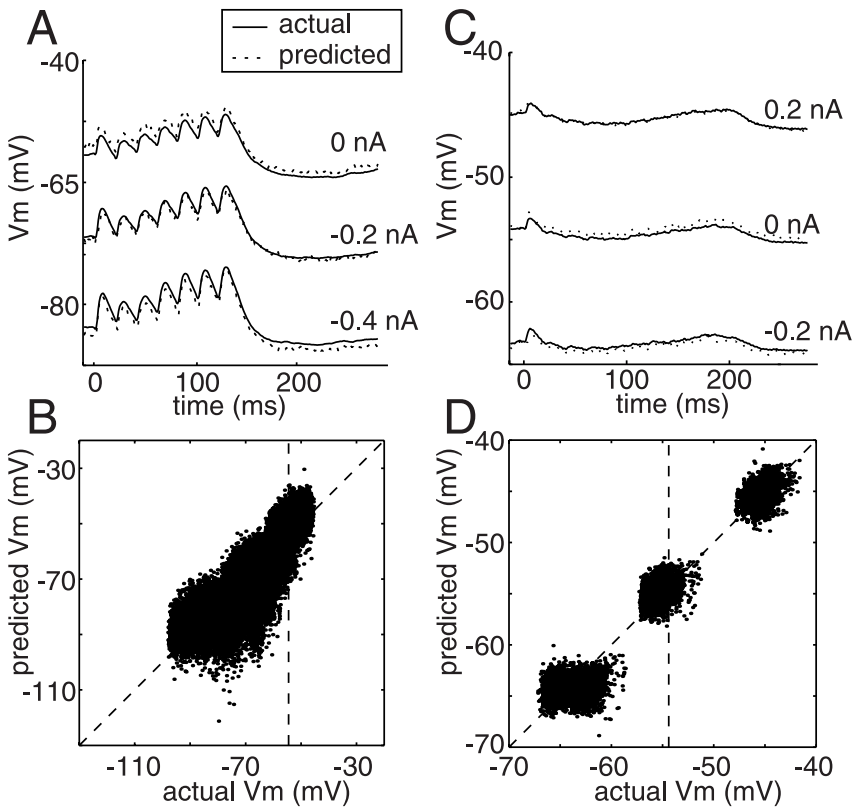

Figure 1. Goodness-of-fit of linear conductance model. $\boldsymbol{A}$, The average measured voltage response (solid lines) and the linear prediction of average voltage response based on our conductance estimates (dotted lines) are shown for each level of current injection in an example cell. $\boldsymbol{B}$, Predicted and measured $V_{m}$, binned at a resolution of $1 \mathrm{~ms}$, are plotted against one another for each point in time and each injected current $(n=39,150)$. Resting potential for this cell was $-55.4 \mathrm{mV}$ (vertical line). The model accounted for $78 \%$ of the variance in the data. $C$ $\boldsymbol{D}$, As in $\boldsymbol{A}$ and $\boldsymbol{B}$, for an example cell for which the linear prediction accounted for $97 \%$ of the variance in the data set (resting potential of $-54.5 \mathrm{mV}$, vertical line; $n=13,920$ ).

the least-squares sense). Estimates of the error on these conductance measurements were made using a nonparametric bootstrap technique (Efron and Tibshirani, 1993) with 1000 repeats.

Our method of estimating synaptic conductances from voltage responses recorded during current injection is similar to the methods used by Anderson et al. (2000). These authors measured conductance changes that occurred during the relatively slow changes in membrane potential evoked by sinusoidal drifting gratings. In this case, the capacitative term from the membrane equation $C_{m} \times d V_{m} / d t$ was negligible and could be omitted without changing the quality of the fits to the data set. In our experiments, the PSPs evoked by electrical stimulation were much shorter in duration and had much higher rates of rise and fall than the responses to gratings. Proper fitting of the data to the membrane equation therefore required us to include the capacitative term (Priebe and Ferster, 2005). Note that this derivation assumes a linear relationship between injected current and the resulting membrane potential, a relationship that would be rendered nonlinear by significant activation of voltage-gated currents, particularly those related to spike generation. We therefore confined our experiments primarily to the use of hyperpolarizing currents and subthreshold stimuli to minimize the activation of voltage-dependent conductances. Even in cells in which the membrane potential covered a significantly wide range of values including depolarization, we saw only modest deviations from linearity (for an example, see Fig. $1 A, B$ ). This suggests that the potential in the soma or dendrites of these neurons is dominated by synaptic conductances, whereas the active conductances responsible for spike production may be concentrated in the initial segment or first node of the axon.

To test whether the assumption of membrane linearity is correct, we used the calculated changes in conductance to re-derive the changes in membrane potential that occurred at each level of injected current, again using the membrane equation (Anderson et al., 2000). Two example cells are shown in Figure 1. In $A$ and $C$, average measured membrane potential is shown as solid lines; linear predictions of membrane potential based on conductance estimates from the membrane equation are shown as dotted lines. In Figure 1, $B$ and $D$, predicted and measured membrane potential are plotted against one another for each point in time and each injected current. For a perfectly linear cell, the points would fall along the line of slope 1 . In the cell in $B$, there is a systematic trend away from perfect linearity. The predicted curve is slightly above the experimental trace at 0 $\mathrm{nA}$, and the opposite is true at $-0.4 \mathrm{nA}$. Even so, and even with the large trial-to-trial variability, the model accounted for $78 \%$ of the variance in the data, which was close to the average for our sample. Figure 1, $C$ and $D$, shows an example cell for which the linear prediction accounted for $97 \%$ of the variance in the data set. For the full sample of monosynaptic and polysynaptic cells in which conductance was measured during trains $(n=10), 77 \pm 22 \%$ of the variance was accounted for mean \pm SD using the full membrane equation.

LGN activity reduction using pressure block of the optic nerve. Spontaneous activity in cells of the LGN was reduced by increasing intraocular pressure (IOP) relative to arterial pressure (Horsten and Winkelman, 1957; Ernest and Potts, 1969). Pressure was applied through a 25 gauge needle inserted into the posterior chamber of the eye and filled with $0.9 \%$ $\mathrm{PBS}, \mathrm{pH}$ 7.3. Pressure blockade was induced by elevating intraocular pressure to $80-220 \mathrm{mmHg}$ for 5-30 s (M. P. Stryker and W. A. Harris, unpublished data) (Takeda et al., 1972). The appropriate pressure and duration of application were determined for each animal by extracellular single-unit and multiunit recordings through the LGN stimulating electrode. Reduced-activity and control trial sets were interleaved, with at least $5 \mathrm{~min}$ of recovery time after the completion of each reduced-activity trial set.

\section{Results}

We examined short-term synaptic depression in in vivo intracellular recordings from 70 neurons of area 17 of cat visual cortex, measuring the amplitude of PSPs evoked by trains of electrical stimuli delivered to the LGN. The intensity of the LGN stimulus was adjusted so that a subthreshold depolarizing PSP was observed in every trial. When stimulus and recording electrodes were properly aligned in corresponding regions of LGN and cortex, stimulus intensity ranged between 130 and $250 \mu \mathrm{A}$. Stimulus trains consisted of 5-10 stimuli at frequencies of 20,50, or 100 $\mathrm{Hz}$. Recorded cells were predominantly located between 400 and $1000 \mu \mathrm{m}$ below the cortical surface, corresponding approximately to layers III-V.

Stimulation of the LGN activates two classes of synaptic inputs: excitatory monosynaptic inputs arising directly from the axons of geniculate neurons, and excitatory and inhibitory polysynaptic inputs mediated by other cortical cells. Synaptic potentials arising from these two distinct pathways differ in latency (Ferster and Lindström, 1983), with disynaptic inputs arriving at least $1 \mathrm{~ms}$ later than monosynaptic inputs (and trisynaptic inputs arriving at least $2 \mathrm{~ms}$ later). Many cortical cells receive both monosynaptic and polysynaptic excitatory inputs. In all cases, we limited our assessment of the effects of repeated stimulation to the earliest component. All cells receive a combination of excitatory and inhibitory inputs. In monosynaptic cells, the earliest excitation precedes the onset of inhibition by at least 1 ms. In polysynaptic cells, the onset of excitation and inhibition are more nearly simultaneous.

The amount of reduction of response amplitude that occurred during the stimulus train varied widely from cell to cell, ranging from almost no reduction at high frequencies $(100 \mathrm{~Hz})$ to a complete abolition of responses at relatively low frequencies $(20 \mathrm{~Hz})$. The response to repeated stimulation of the LGN is shown in Figure 2, $A$ and $B$, for a cell that showed relatively little reduction in response during the course of a $50 \mathrm{~Hz}$ train. By our criteria (see below), this cell received direct, monosynaptic input from the LGN, as indicated by the short latency $(2.1 \mathrm{~ms})$ and small jitter of the responses. The average voltage response to 16 repetitions of a $50 \mathrm{~Hz}$ train of geniculate stimuli is shown in the top panel of 

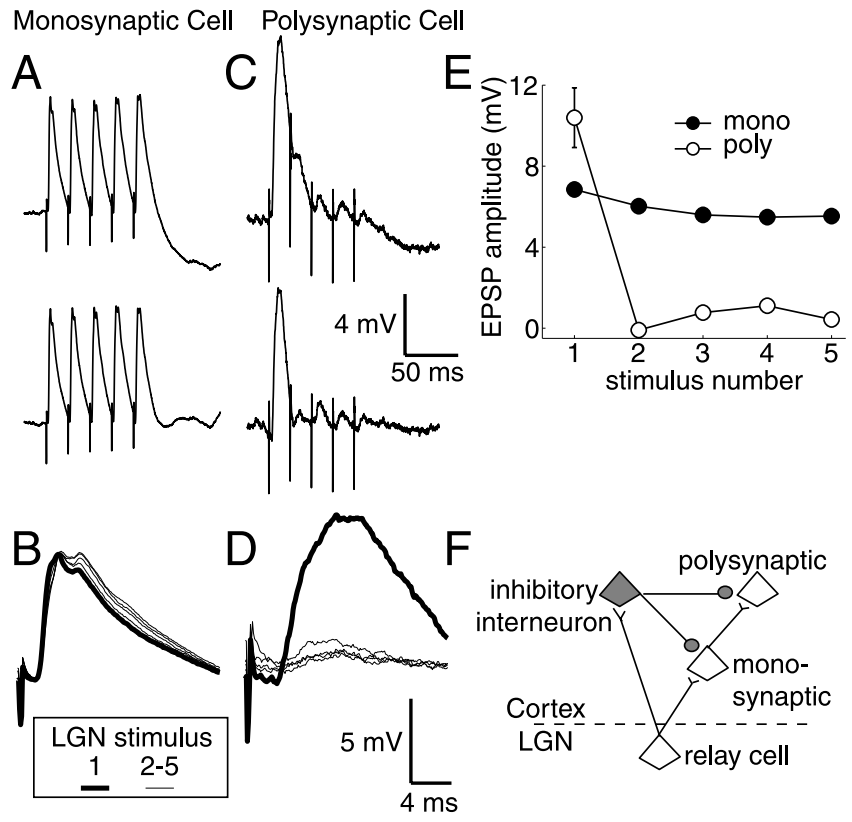

Figure 2. Responses to repeated LGN stimulation. $A$, Top trace, Voltage response of a cortical cell that received monosynaptic input from the $L G N$ to a five impulse, $50 \mathrm{~Hz}$ train of electrical stimuli. Bottom trace, Same traces, with slow trends removed as described in Materials and Methods. Average of 16 trials. LGN stimulus amplitude of $200 \mu$ A. Resting potential of -60 $\mathrm{mV}$. B, PSPs from $\boldsymbol{A}$, bottom trace, aligned on the LGN stimulus. The thick trace is the first PSP. $C$, As in $A$, for a cell that received only polysynaptic input from the LGN. Average of 16 trials. LGN stimulus amplitude of $225 \mu \mathrm{A}$. Resting potential of $-71 \mathrm{mV}$. D, Superimposed responses to individual stimuli, aligned on the LGN stimulus. $E$, PSP amplitude as a function of stimulus position in the train. Filled symbols, Data for the monosynaptic cell in $\boldsymbol{A}$ and $\boldsymbol{B}$; open symbols, data for the polysynaptic cell in $\boldsymbol{C}$ and $\boldsymbol{D}$. Error bars are SE. $\boldsymbol{F}$, Diagram showing the connectivity of monosynaptic and polysynaptic neurons. Both cell types are thought to receive input from cortical inhibitory interneurons. Monosynaptic cells receive substantial excitatory input from the $L G N$, whereas polysynaptic cells receive little direct thalamic input and are primarily driven by excitatory input from other cortical cells.

Figure $2 \mathrm{~A}$. The response to the train consisted of a series of brief depolarizing potentials followed by a large, long-lasting hyperpolarization to below the resting potential (most likely $\mathrm{GABA}_{\mathrm{B}}$ mediated). The bottom panel of Figure $2 A$ shows the same trace after application of our detrending procedure (see Materials and Methods). The individual responses to each stimulus in the train are superimposed in Figure $2 B$. The thick line shows the response to the first stimulus; the thin lines show the responses to the second to fifth stimuli. The amplitudes of these PSPs relative to the baseline (measured just after to each stimulus) are plotted in Figure $2 E$ (filled symbols). In this cell, the amplitude of the response declines slightly during the train, with the fifth response being $84 \%$ of the first.

A cell that showed profound response reduction to repeated geniculate stimulation is shown in Figure 2, $C$ and $D$. The long latency of the response to LGN stimulation $(3.1 \mathrm{~ms})$ indicated that this cell likely received no direct, monosynaptic input from the LGN but instead received its excitatory input via other cortical cells. The individual responses are superimposed in $D$, and their amplitudes are plotted in $E$ (open symbols). The first stimulus evoked a large, slowly decaying PSP (Fig. $2 D$, thick trace). The second and subsequent responses were reduced in amplitude to $<10 \%$ of the first. Nearly the entire reduction in response to repeated stimulation occurred after the first stimulus in the train. This cell also showed a hyperpolarization below baseline after the train, although it is smaller than that of the cell in Figure $2 \mathrm{~A}$. In general, there was no correlation between the slow trends in

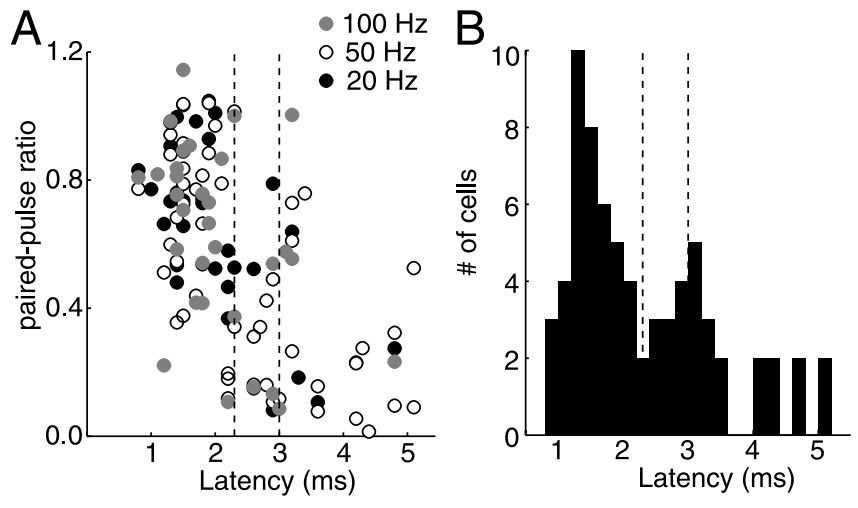

Figure 3. Relationship between latency and PSP decrement. $\boldsymbol{A}$, At all frequencies tested, there was a significant negative correlation between PSP latency and paired-pulse ratio. Dashed lines show our criteria for putative monosynaptic and polysynaptic neurons. Cells tested at more than one frequency are represented more than once. $\boldsymbol{B}$, Histogram of the latency of the first PSP for all 70 cells tested. Latency was determined from the response to the first stimulus at all frequencies combined. Dashed lines show the same criteria as those in $\boldsymbol{A}$.

membrane potential and the amount of PSP reduction during the train.

Because we are specifically interested in measuring the synaptic depression in the direct, thalamocortical input to cortical cells, we examined the correlation between PSP latency and reduction of PSP amplitude between the first and second stimulus (Fig. 3A). As suggested by the examples in Figure 2, latency and decrement were highly correlated, large decrements being associated with long latencies $(20 \mathrm{~Hz}, r=-0.47 ; 50 \mathrm{~Hz}, r=-0.46 ; 100 \mathrm{~Hz}, r=$ $-0.48)$.

As in previous studies (Ferster and Lindström, 1983; Chung and Ferster, 1998), we chose latency criteria for monosynaptic and polysynaptic inputs based on the distribution of observed latencies. This distribution is shown in Figure $3 B$. Cells with latencies of less than or equal to 2.3 ms were classified as monosynaptic; cells with latencies of greater than or equal to $3.0 \mathrm{~ms}$ were classified as polysynaptic. Those in between 2.3 and 3.0 were left unclassified (Chung and Ferster, 1998). Cells with short-latency responses had less variability in the amplitude and latency ("jitter") than cells with long-latency responses. Polysynaptic PSPs tended to be smaller ( $3.3 \mathrm{mV}$ on average compared with $5.6 \mathrm{mV}$ for monosynaptic cells) and slower to rise and decay.

Of the cells in our sample, 42 were classified as receiving monosynaptic input from the LGN, and 19 were classified as receiving polysynaptic input. Nine cells of intermediate latency were not classified. Thirty-two cells (22 monosynaptic, 6 polysynaptic, and 4 unclassified) were tested at more than one frequency. Figure $4 A$, for example, shows the responses at all three frequencies of a single cell with monosynaptic input. The example traces are shown with different time bases so that the responses are aligned.

Plots of mean PSP amplitude as a function of stimulus number are shown for each recorded monosynaptic cell in Figure $4 B$ and for each polysynaptic cell in Figure 4C. Normalized averages for the two populations are shown in Figure $4 D$. Monosynaptic cells (filled symbols) showed a small decrement in response amplitude that reached its maximum by the second or third stimulus, followed by a partial recovery. For polysynaptic cells (open symbols), the response decrement between the first and second stimulus is greater at all frequencies than that shown for monosynaptic cells, with profound decrements even at $20 \mathrm{~Hz}$. A slight recovery from the maximum decrement can be observed at 50 


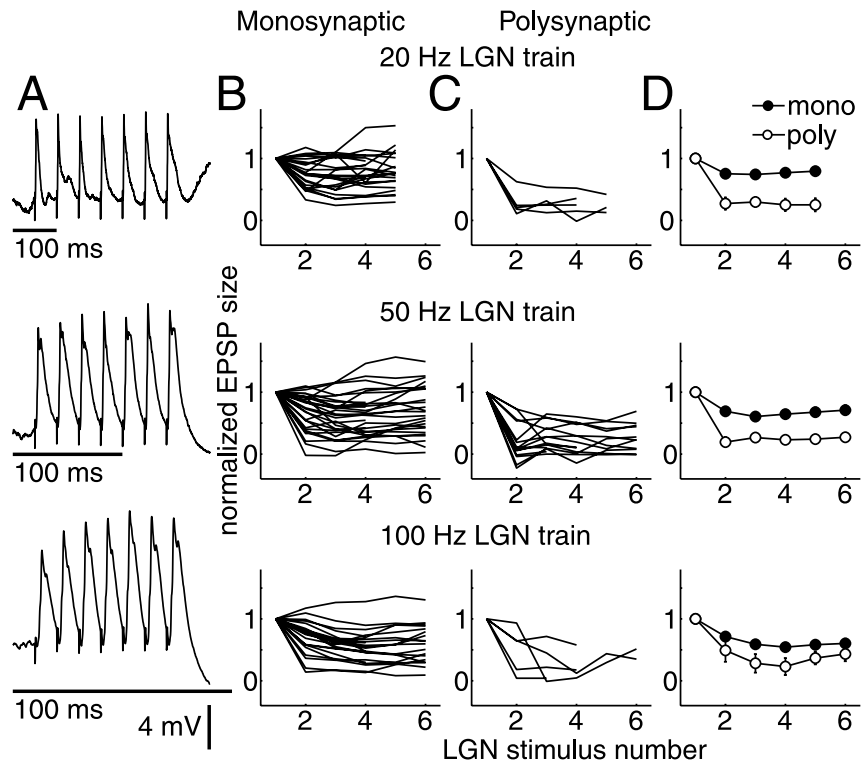

Figure 4. Effects of stimulus frequency on PSP decrement. $A$, Responses of a second putative monosynaptic cell to stimulation at 20,50 , and $100 \mathrm{~Hz}$ (resting potential of $-75.5 \mathrm{mV}$; average of 16 trials). $\boldsymbol{B}, \boldsymbol{C}$, Normalized PSP size as a function of stimulus number for two classes of cells defined by our criteria. D, Normalized PSP size as a function of stimulus number averaged across cells for 20,50, and $100 \mathrm{~Hz}$. Filled symbols, Monosynaptic neurons; open symbols, polysynaptic neurons $(20 \mathrm{~Hz}, n=24$ monosynaptic, $n=5$ polysynaptic; $50 \mathrm{~Hz}, n=30$ monosynaptic, $n=15$ polysynaptic; $100 \mathrm{~Hz}, n=23$ monosynaptic, $n=5$ polysynaptic). Error bars are SE.

and $100 \mathrm{~Hz}$. For a $20 \mathrm{~Hz}$ train, the average response to the fifth stimulus was $79.5 \pm 6.5 \%$ of the response to the first stimulus for monosynaptic cells and $25.2 \pm 7.5 \%$ for polysynaptic cells. For a $50 \mathrm{~Hz}$ train, the average response to the sixth stimulus was $70.9 \pm$ $7.4 \%$ of the first stimulus for monosynaptic cells and $27.1 \pm 6.1 \%$ for polysynaptic cells. For the $100 \mathrm{~Hz}$ train, the average response to the sixth stimulus was $60.4 \pm 6.6 \%$ of the response to the first stimulus for monosynaptic cells and $43.3 \pm 5.8 \%$ for polysynaptic cells.

\section{Cortical stimulation occludes response reduction in cells with polysynaptic geniculate input}

There are a number of mechanisms that might account for the striking decrement in the responses of polysynaptic cells after the first stimulus in a train. (1) Synapses onto the recorded cell from the presynaptic cortical neurons might depress heavily after a single LGN shock. (2) The first stimulus might evoke a strong inhibitory shunt in the recorded cell, which then reduces the amplitude of subsequent PSPs. (3) The presynaptic cortical neurons generating the PSP might fail to fire in response to the second and subsequent stimuli because of long-lasting inhibition evoked by the first stimulus. (4) The presynaptic neurons generating the polysynaptic PSP might fail to fire because of depression at the geniculocortical synapses providing their input. Even a modest amount of depression could be amplified by the nonlinearity of threshold to suppress firing. The first three possibilities are similar to one another in that properties of the cortical circuit, and not depression at the geniculocortical synapse, suppress the response of cortical cells to repeated stimulation.

To test whether it is the cortical circuit or thalamocortical depression that is responsible for the strong decrement in polysynaptic cells during a train, we attempted to occlude the effects of the first geniculate stimulus by delivering a shock di- rectly to the cortex just before the stimulus train. If a cortical mechanism were responsible for reducing the size of the polysynaptic LGN-evoked PSPs later in the train, shocking the cortex directly should mimic the effects of the first geniculate stimulus. If, conversely, depression had occurred at the synapse between the LGN and cortical cells presynaptic to the recorded cell, then the cortical shock should have little effect.

For 39 cells in our sample ( 21 monosynaptic, 13 polysynaptic, and 5 unclassified) we recorded responses to a train of LGN stimuli delivered $20 \mathrm{~ms}$ after a shock to the superficial layers of the cortex. Not all cells were tested at all frequencies; 16 cells were tested at two or three frequencies. The cortical stimulating electrode was placed no deeper than $300 \mu \mathrm{m}$ from the surface, and the stimulation amplitude was kept below $500 \mu \mathrm{A}$ to avoid direct stimulation of geniculocortical terminals (Chung and Ferster, 1998). The horizontal distance between the cortical stimulating electrode and the recording electrode was $500 \mu \mathrm{m}$ or less. Cortical stimulation evokes a brief EPSP and long-lasting IPSP with nearly identical latencies (Chung and Ferster, 1998), resulting most often in a net depolarization early on in the trace (depending on the relative sizes of the simultaneous EPSP and IPSP), followed by long-lasting hyperpolarization as the EPSP decays. The amplitude of the cortical shock was adjusted to evoke a longlasting hyperpolarization when delivered alone. On average, the amplitude necessary to produce this hyperpolarization in shortlatency cells was slightly larger $(268 \mu \mathrm{A} ; n=21)$ than for longlatency cells $(215 \mu \mathrm{A} ; n=13)$. A depolarizing PSP was often visible at the start of the trace; there was a small (but not statistically significant) difference in the average size of this depolarization between groups (monosynaptic, $6.4 \pm 1.2 \mathrm{mV}, n=21$; polysynaptic, $7.5 \pm 1.8 \mathrm{mV}, n=13$ ).

Monosynaptic PSPs evoked from the LGN were relatively unaffected by a preceding cortical shock. The black traces in Figure 5, $A$ and $B$, for example, show the response of a cell with monosynaptic geniculate input to a $50 \mathrm{~Hz}$ train of LGN stimuli. The gray traces show responses to the same train of LGN stimuli preceded by a single shock to the cortex. Response shapes and amplitudes are otherwise very similar (Fig. 5C). This similarity would suggest that the inhibition evoked by the cortical shock does not strongly shunt the subsequent LGN-evoked EPSPs.

The effects of cortical stimulation are shown for a polysynaptic cell in Figure 5, D and $E$. The distance between the cortical stimulating and recording electrodes, and the stimulus amplitudes, are the same as in Figure 5, $A$ and $B$. In this cell, as in most polysynaptic cells, the cortical shock had a much more pronounced effect on the response to the first shock in the train of LGN stimuli (Fig. 5D,E), although the cortical shock alone hyperpolarized the cell only mildly. LGN stimulation in the absence of the cortical shock produced a robust response to the first stimulus in the train (Fig. 5D, black trace, E, thick black trace), whereas subsequent stimuli produced a much smaller response (Fig. $5 E$, thin black traces). When the cortical shock immediately preceded the LGN stimulation train, the response to the first stimulus in the train was nearly abolished (Fig. 5D,E, gray traces, $F$ ).

Averaged data for the cortical conditioning experiment are shown in Figure 6. In monosynaptic cells (Fig. 6A, filled symbols), a preceding cortical shock reduced the amplitude of the response to the first LGN stimulus to $88 \%$ of control (not significant by paired $t$ test, $p>0.1$ ). In polysynaptic cells, the preceding cortical shock reduced the average size of the response to the first LGN stimulus to $43 \%$ of control ( $p<0.05$ by paired $t$ test) so that it was similar in amplitude to subsequent responses that were 


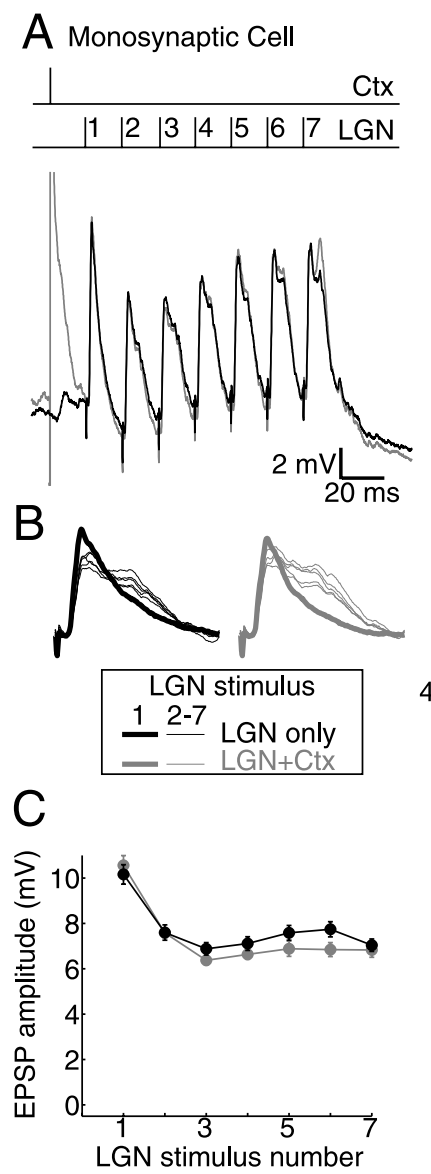

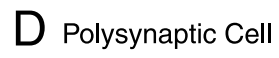
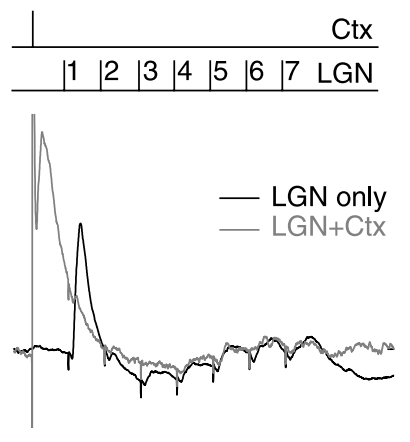

$E$

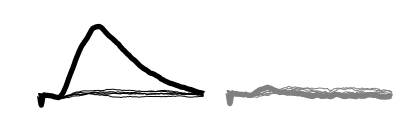

$$
4 \mathrm{mVL}
$$

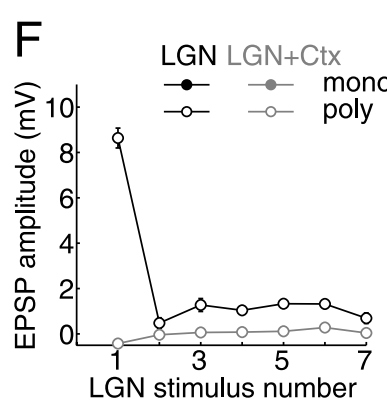

Figure 5. Response to repeated LGN stimulation after a single shock to the cortex. $\boldsymbol{A}$, Response of a monosynaptic cell to $L G N$ stimulation alone (black) and $L G N$ and cortical stimulation together (gray); resting potential of $-72 \mathrm{mV}$. The relative timing of the stimuli is shown above the traces. Traces show the average of 16 trials. The cortical shock amplitude was $200 \mu$ A. $\boldsymbol{B}$, Superimposed response to the $L G N$ stimuli, with slow trends removed. The thick trace shows the first LGN-evoked response; thinner traces show subsequent responses. As in $A$, gray and black traces were collected with and without preceding cortical stimulation. $\boldsymbol{D}, \boldsymbol{E}$, Same as $\boldsymbol{A}$ and $\boldsymbol{B}$ for a polysynaptic cell, average of nine trials; resting potential of $-61 \mathrm{mV}$. The cortical shock amplitude was $200 \mu \mathrm{A}$. C, F, Amplitude of the LGN-evoked response as a function of stimulus position in the train with cortical stimulation (gray plots) or without (black plots). Filled symbols, Monosynaptic cell; open symbols, polysynaptic cell. Ctx, Cortex.

recorded either with or without cortical conditioning (Fig. 6, open symbols).

In Figure $6 B$, we compare the effects of a cortical conditioning stimulus with the effects of the first stimulus in the LGN train. The black points show the response to the second stimulus in the train plotted against the response the first stimulus in the train (without cortical stimulation). The gray points plot the response to the first stimulus in the LGN train after cortical stimulation against the response to the first stimulus without cortical stimulation. For monosynaptic cells (Fig. $6 \mathrm{~B}$, top), the conditioning stimulus, whether delivered to the LGN or cortex, has a similar, small effect on the subsequent response. For polysynaptic cells (Fig. 6B, bottom), the conditioning shock to the LGN and to the cortex again have nearly identical effects, but, in this case, the effect is to greatly reduce the size of the subsequent response. The small effect of cortical shock on the responses of the monosynaptic cells supports the conclusion that the LGN-evoked PSPs arise primarily from monosynaptic thalamic input and not from polysynaptic input via other cortical cells. The large effect of cortical shock on the polysynaptic cells supports the conclusion that the reduction in response during the LGN train
A
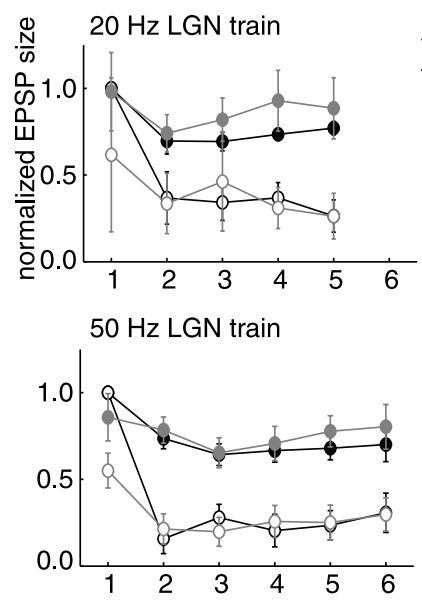

B
$\perp 12 \ldots$ Ctx
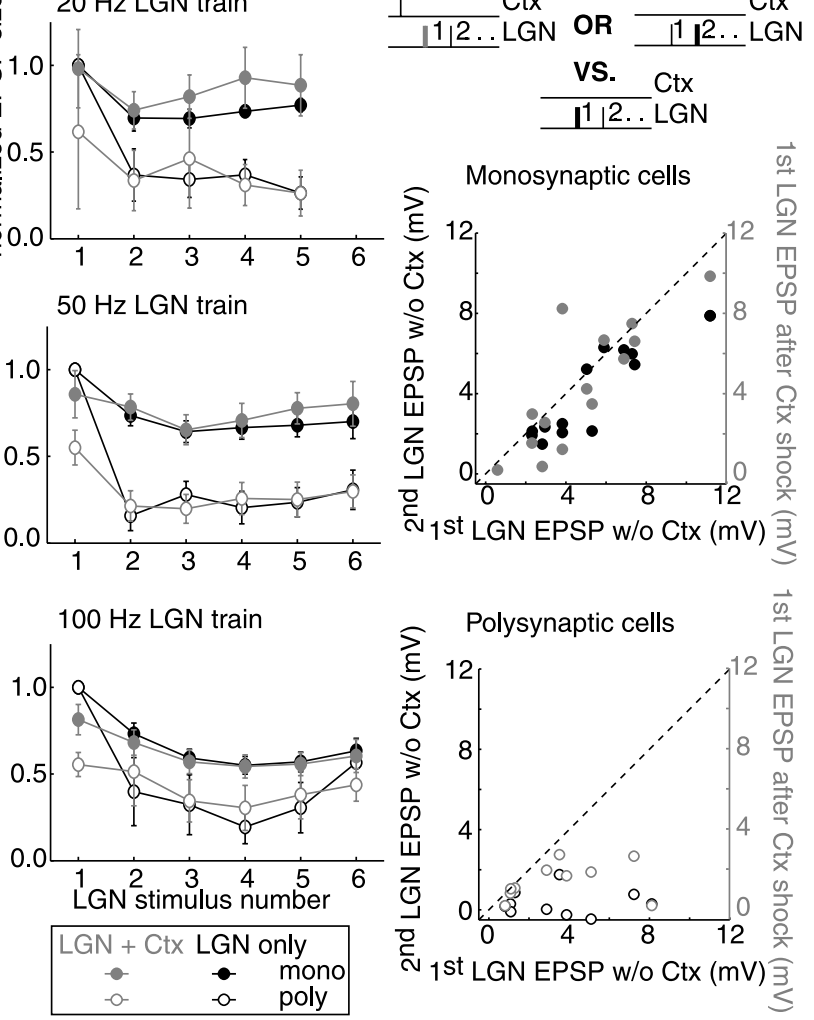

Figure 6. Effects of cortical stimulation on the responses to rapid LGN stimulation averaged over the sample. $A$, Average amplitude of $L G N$ responses of monosynaptic cells (filled symbols) and polysynaptic cells (open symbols) at 20,50 , and $100 \mathrm{~Hz}$ with preceding cortical stimulation (gray) and without (black). $\boldsymbol{B}$, Comparison of effects of preceding shocks. The schematic shows which PSPs are being compared in the graphs below. Gray symbols compare the response to an LGN shock given 20 ms after cortical stimulation with the response to the LGN shock alone. Black symbols compare the response to the second stimulus in a $50 \mathrm{~Hz} \mathrm{LGN}$ train (with no cortical stimulation) to the response to the first LGN shock in the train. Top, Monosynaptic cells; there was a good correlation for both sets of points. Bottom, Polysynaptic cells; there was no correlation for either set of points in the polysynaptic data. Ctx, Cortex.

is the result of intracortical effects and not thalamocortical depression.

\section{Conductance changes associated with electrical stimulation}

Because our recordings were made in vivo, the responses evoked by stimulation of the LGN necessarily contained several components, including monosynaptic and polysynaptic EPSPs, and partially overlapping IPSPs. It is therefore difficult to assign any observed effects unequivocally to a decrease in excitation or to an increase in inhibition evoked by the stimulus. To isolate some of these components and measure the effects of repeated stimulation on each of them separately, we have estimated the LGNevoked synaptic conductances. We recorded the membrane potential responses while injecting steady currents of different amplitudes into the recorded cell and applied the resulting records of potential to the membrane equation (see Materials and Methods).

In 13 cells ( 5 monosynaptic and 8 polysynaptic), the average resting input resistance, $R_{m}$, was $46.5 \pm 7.6 \mathrm{M} \Omega$. The average membrane time constant, $\tau$, was $17.9 \pm 2.1 \mathrm{~ms}$. There was no difference in either of these parameters between monosynaptic and polysynaptic cells $(p>0.2)$. In a cell with monosynaptic input, a $50 \mathrm{~Hz}$ LGN stimulus train evoked an increase in total 


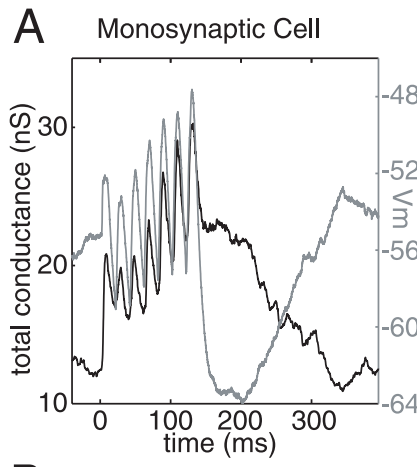

$\mathrm{B}$
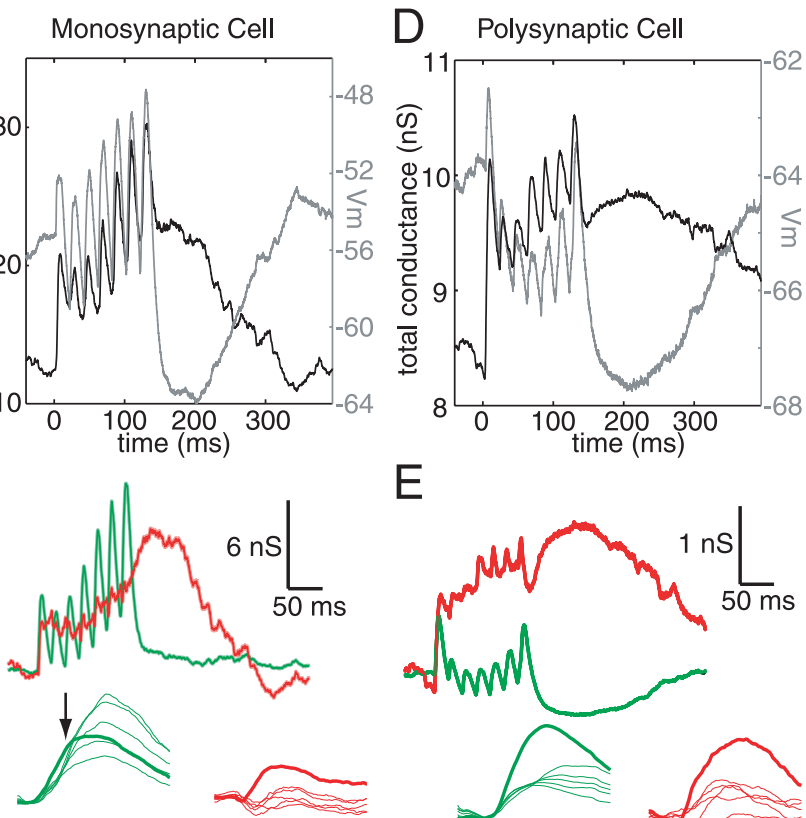

$\mathrm{E}$

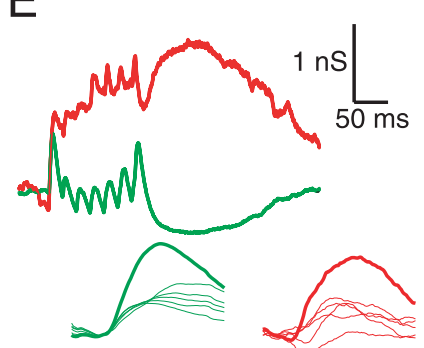

$2 n S L$

$2 \mathrm{~ms}$

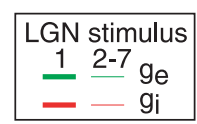

$0.2 \mathrm{nS} L$

$2 \mathrm{~ms}$

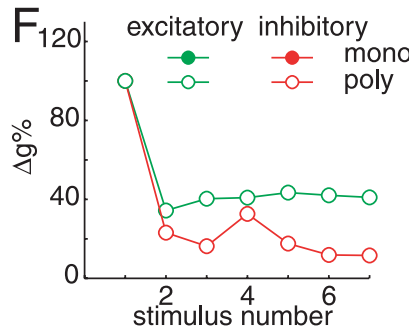

Figure 7. Conductance measurements. $\boldsymbol{A}$, Voltage response (gray) and estimated total conductance (black) evoked in a monosynaptic cell by $50 \mathrm{~Hz}$ stimulation of the LGN (average of 30 trials). Time 0 is the time of the first LGN stimulus. Conductance was calculated in $1 \mathrm{~ms}$ bins. $\boldsymbol{B}$ Top, Excitatory and inhibitory components of conductance change for the cell in $\boldsymbol{A}$. Shaded $95 \%$ confidence intervals were calculated from 1000 repetitions of a nonparametric bootstrap analysis but are barely visible on the excitatory traces because they are only slightly thicker than the trace itself. Bottom, Superimposed conductance changes associated with each LGN-evoked response, with the first response shown as a thick trace. $\boldsymbol{D}, \boldsymbol{E}$, As in $\boldsymbol{A}$ and $\boldsymbol{B}$ for a polysynaptic cell, average of 30 trials. $\boldsymbol{E}, \boldsymbol{F}$, Relative size of the conductance changes after each LGN stimulus, normalized to the size of the conductance change after the first stimulus. Green, Excitatory conductance changes; red, inhibitory conductance changes; filled symbols, monosynaptic (mono) cell; open symbols, polysynaptic (poly) cell.

conductance, which consisted of a series of transient increases superimposed on a gradual increase (Fig. $7 \mathrm{~A}$, black trace). The increase decayed slowly between 50 and $300 \mathrm{~ms}$ after the end of the train. The gray trace shows the voltage response to the stimulus train when no current was injected.

Figure $7 B$ shows the decomposition of the conductance change into its stimulus-evoked excitatory and inhibitory components, $g_{e}$ and $g_{i}$. Note that $g_{e}$ and $g_{i}$ represent the change in inhibitory and excitatory conductance relative to their resting levels and can therefore go below zero (Materials and Methods). The amplitudes of the transient changes in conductance were measured using the same detrending procedure used for voltage traces (see Materials and Methods). The amplitude $\left(\Delta g_{e}\right.$ or $\left.\Delta g_{i}\right)$ was measured as the change in conductance from the time just after the stimulus to the point in time when the first response reached $90 \%$ of its maximum (arrow) for each stimulus in the
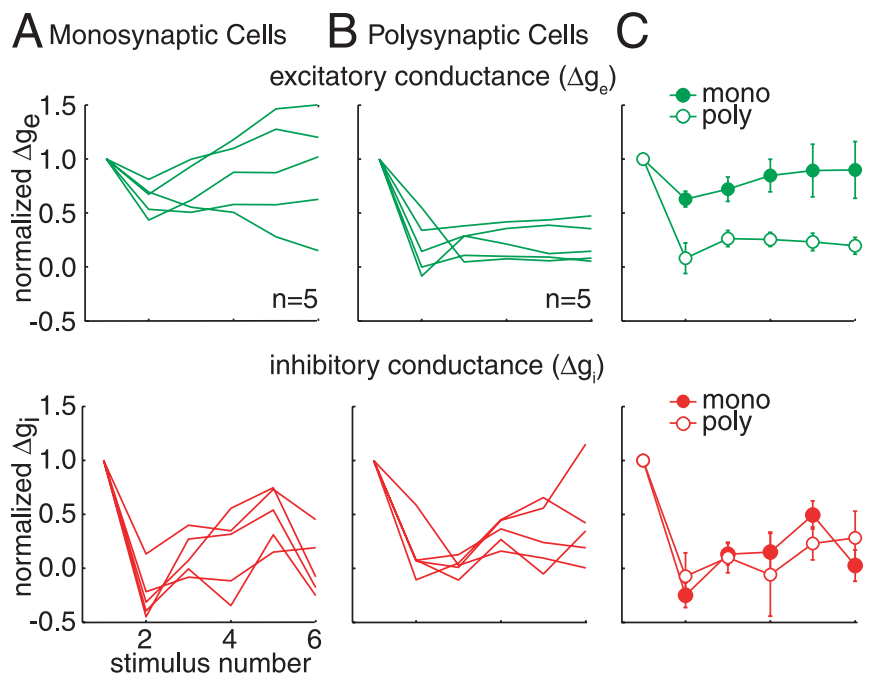

Figure 8. LGN-evoked excitatory and inhibitory conductance for the sample. $A$, The size of the conductance change after each $L G N$ stimulus in a $50 \mathrm{~Hz}$ train is shown, normalized to the size of the first response, for monosynaptic cells (green, excitatory; red, inhibitory). $\boldsymbol{B}$, As in $\boldsymbol{A}$, but for polysynaptic cells. $\boldsymbol{C}$, Averages of the data in $\boldsymbol{A}$ and $\boldsymbol{B}$. Filled symbols, Monosynaptic (mono) cells; open symbols, polysynaptic (poly) cells. Error bars are SE.

train. Note that, in the response to stimuli 2-7, a long-latency augmenting component follows the monosynaptic EPSP. Response amplitude as a function of stimulus number is plotted in Figure $7 C$. The increases in $g_{e}$ were brief enough to decay nearly to baseline between each stimulus. The amplitude of the early part of these transients changed little over the course of the train. In contrast, the transient increases in $g_{i}$ decayed much more slowly (Douglas and Martin, 1991; Anderson et al., 2000), so that the inhibitory conductance stayed elevated between stimuli. Unlike the excitatory conductance in this cell (but very much like the amplitude of polysynaptic EPSPs in Fig. 7D-F), the amplitude of the inhibitory transients fell dramatically after the first stimulus.

Conductance measurements for an example polysynaptic cell are shown in Figure 7D-F. In this cell, the amplitudes of both the excitatory and inhibitory conductance transients were significantly reduced after the first stimulus (Fig. $7 F$ ). Whereas the longer decay time of the IPSPs kept the inhibitory conductance high between stimuli, the excitatory conductance decayed back to baseline, or even below, as if between stimuli the train suppresses a tonic level of excitatory input. Consistent with previous reports of membrane potential changes (Ferster and Lindström, 1983) and conductance changes after a single LGN stimulus (Anderson et al., 2000), we found that the latency of the inhibitory conductance change, $\Delta g_{i}$, was longer in monosynaptic cells $(3.7 \pm 0.5 \mathrm{~ms}$ on average) than that of the excitatory conductance change, $\Delta g_{e}$ $(1.9 \pm 0.3 \mathrm{~ms})$. In polysynaptic cells, latencies for both conductance changes were similar $\left(\Delta g_{e}, 3.6 \pm 0.2 \mathrm{~ms} ; \Delta g_{i}, 3.2 \pm 0.2 \mathrm{~ms}\right)$.

The differences between cells with monosynaptic and polysynaptic input from the LGN seen in Figure 7 were consistent across the sample of cells $(n=5$ for monosynaptic cells and $n=$ 5 for polysynaptic cells; three of the polysynaptic cells for which we estimated resting conductance parameters were not tested with a $50 \mathrm{~Hz}$ train). The amplitudes of the transient components of $g_{e}$ and $g_{i}$ are plotted as a function of stimulus number in Figure $8, A$ and $B$, for each cell. These data are averaged in Figure $8 C$. During the train of LGN shocks, monosynaptic cells showed an immediate reduction in the size of the evoked excitatory conductance, to $62.9 \%$ of the first response on average, followed by a 
recovery. Last responses were not significantly different from first responses for our sample $(p>0.2)$. For polysynaptic neurons, excitatory drive was nearly abolished for all responses except the first (decreased to $10 \%$ of the first response on average; $p<$ $0.005)$. Inhibitory conductance transients were decreased significantly with repeated stimulation for both cell classes (monosynaptic, $p<0.005$; polysynaptic, $p<0.01$ ). These results suggest that the dramatic drop in EPSP size in polysynaptic cells reflects a decrease in excitatory synaptic input, originating from depression at the thalamocortical synapse, depression of excitatory intracortical input, or failure of the presynaptic neurons to fire as a result of inhibition from the preceding shock.

\section{Reducing spontaneous activity in the LGN}

In the rat somatosensory system, neuromodulators that increase the rate of spontaneous firing in the thalamus reduce the amount of paired-pulse depression induced by electrical stimulation of the thalamus. It has therefore been suggested that the spontaneous activity itself depresses the synapses, and that additional stimulus-evoked activity does not depress them any further (Castro-Alamancos and Oldford, 2002; Castro-Alamancos, 2004). In contrast to rat thalamic neurons under urethane anesthesia, which (without applied neuromodulators) have little spontaneous activity $[<1 \mathrm{~Hz}$ (M. Castro-Alamancos, personal communication)], LGN relay cells in the pentothal-anesthetized cat have fairly high spontaneous rates $(5-20 \mathrm{~Hz})$, although lower than those in an awake cat looking at a blank monitor $[20-40 \mathrm{~Hz}$ (T. Weyand, personal communication)]. The thalamocortical synapses in our preparation may therefore already be depressed by this activity and so do not depress further during the stimulus train.

To test the effects of spontaneous activity in the LGN on the state of depression at the thalamocortical synapse, we reduced this activity by increasing intraocular pressure. Because spontaneous activity in the LGN is partly inherited from the retinal ganglion cells, increased intraocular pressure, which occludes blood flow to the retina, silences retinal ganglion cells (Takeda et al., 1972) and reduces spontaneous firing in the LGN (Stryker and Harris, unpublished data). Figure $9 A$ shows a histogram of the normalized spike discharge of typical extracellularly recorded single units in the LGN. When the pressure in the posterior chamber of both eyes was increased to $80 \mathrm{mmHg}$ for $5 \mathrm{~s}$ (gray shaded region), the spontaneous activity decreased by $\sim 50 \%$. The cells recovered fully within $2 \mathrm{~min}$ after the pressure was released. In eight cells from several animals, the mean firing rate in the control condition was $11.8 \pm 2.9$ spikes/s and $4.1 \pm 1.4$ spikes/s in the blockade condition. The median decrease in spontaneous rate with increased intraocular pressure was $61 \%$. To ensure full recovery between periods of increased IOP, we allowed at least 5 min to elapse after each application. In Figure $9 B$, we show inactivation and recovery of single units in the LGN after $30 \mathrm{~s}$ of increased IOP (average of normalized responses from four cells). A short burst of activity at the onset of the pressure increase is visible, followed by the reduction in spontaneous activity. Recovery was complete within 1-2 min, and firing rates after recovery were stable. Visual responses (to drifting gratings) were reduced even more strongly than spontaneous activity during pressure blockade.

We compared cortical PSPs evoked by $50 \mathrm{~Hz}$ trains of electrical stimulation in the LGN with and without elevated intraocular pressure. Results for one monosynaptic cell are shown in Figure $9 C-E$. In the control condition (black traces), the transient PSP evoked from the LGN decreased slightly but recovered to its ini-
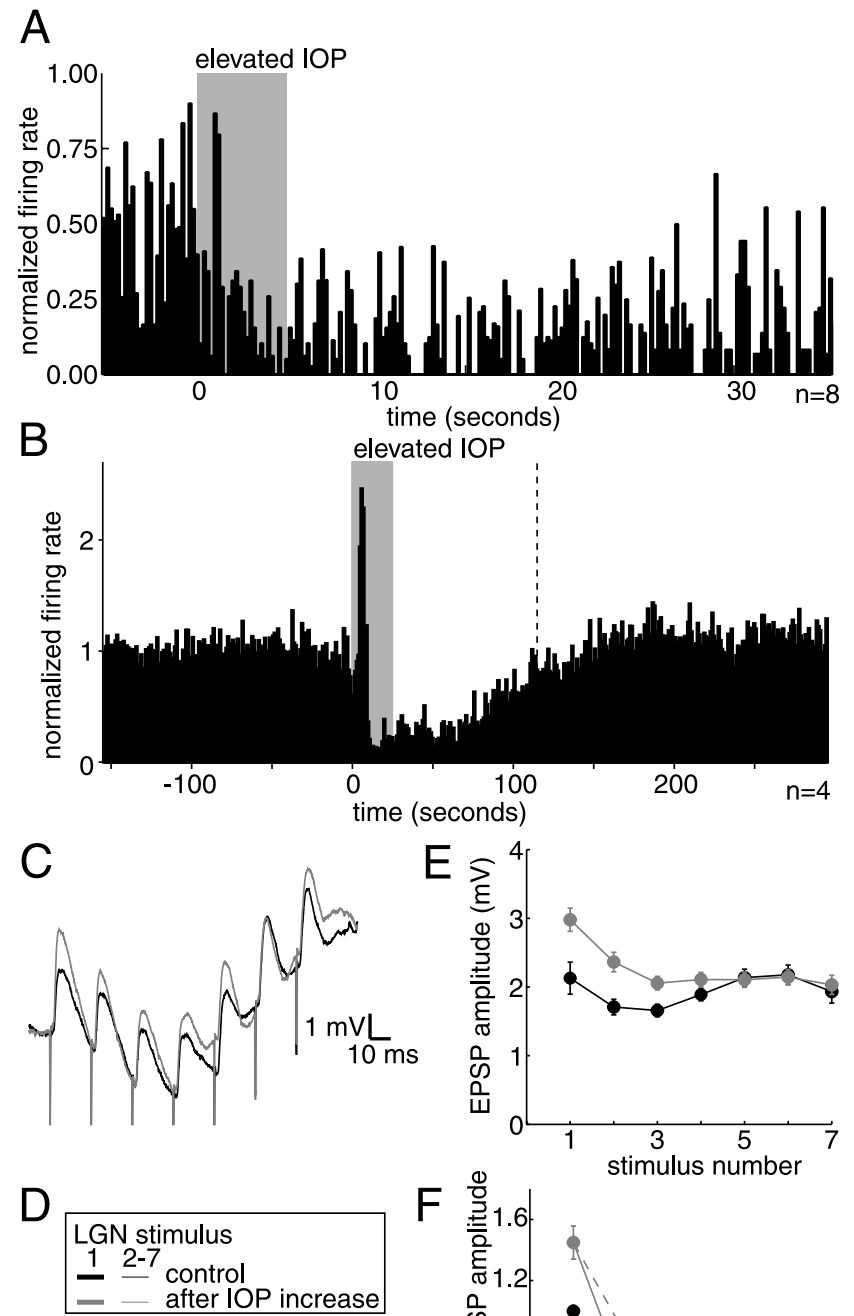

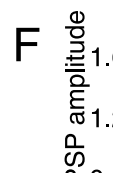

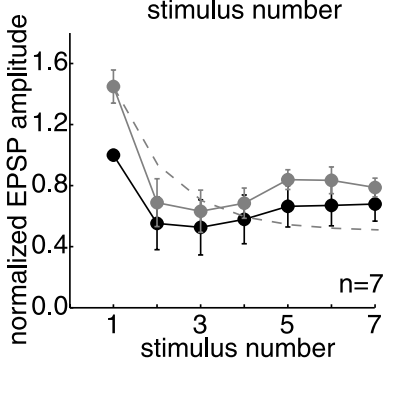

Figure 9. Effects of $L G N$ activity reduction on response to $L G N$ stimulation. $\boldsymbol{A}$, Spontaneous activity in single-unit LGN recordings before, during, and after a period of increased intraocular pressure ( $80-150 \mathrm{mmHg}$ for $5 \mathrm{~s}$; gray shaded region). $\boldsymbol{B}$, Spontaneous activity in single-unit LGN recordings showing full recovery after increased IOP $(150-200 \mathrm{mmHg})$ for $30 \mathrm{~s}$. Dashed line shows time at which normalized firing rate is no longer significantly different from initial firing rate. Mean firing rate before inactivation was $8.8 \pm 1.3$ spikes/s and after inactivation was $10.1 \pm 3.0$ spikes/s. C, Response to $50 \mathrm{~Hz}$ train of LGN stimuli in a monosynaptic neuron with LGN activity reduction (gray) and without (black); resting potential of $-73 \mathrm{mV}$. Average of 80 traces. D, Data in $\boldsymbol{C}$, with slow trends subtracted and aligned on LGN stimulus. Thick traces show first PSPs, and thin traces show subsequent PSPs. $\boldsymbol{E}$, Average PSP size as a function of position in the stimulus train for the cell in $\boldsymbol{C}$ and $\boldsymbol{D}$ for control condition (black) and reduced LGN activity (gray). Error bars are SE. F, Average PSP size for our sample of monosynaptic cells, normalized to the size of the first PSP in the control condition. Error bars are SE. Dotted gray line shows predictions from in vitro experiments (Stratford et al., 1996; Kayser et al., 2001); for details, see Discussion.

tial amplitude by the end of the train. When intraocular pressure was raised to $90 \mathrm{mmHg}$ (gray traces), the first PSP in the train (Fig. 9D, bold traces) increased by $50 \%$, but later PSPs were similar to the control conditions.

Reducing spontaneous activity in the LGN consistently in- 
creased the size of the first PSP evoked by electrical stimulation in the seven monosynaptic cells tested. Figure $9 F$ shows a plot of averaged PSP size versus position in the train for the seven cells, normalized to the size of the first PSP in the control condition. The black plot shows control data and is similar to the responses to $50 \mathrm{~Hz}$ trains for the whole population shown in Figure $4 D$. The gray plot shows data for the monosynaptic cells in the inactivated condition. High intraocular pressure increased the amplitude of the first PSP by $44.9 \pm 11 \%$ on average but had little effect on later PSPs.

The decrement in response amplitude between the first and second stimulus observed during blockade of retinal activity suggest that spontaneous activity might normally maintain the geniculocortical synapses in a tonic state of depression. Silencing that activity then allows the synapses to recover from depression during the 1.75 s intertrain interval, but a single shock to the LGN restores depression to its normal level. One question that arises is whether, during suppression of LGN activity, the $1.75 \mathrm{~s}$ interval between trains is long enough to permit complete recovery from depression. To address this question, in each block of 16 trains (see Materials and Methods), we examined the responses to the first train, which followed the last train in the preceding block by at least 5 and often $>100 \mathrm{~s}$. We found no difference in the amplitude of the first PSP between trains with short and long intertrain intervals ( $p>0.3$ by paired $t$ test). In addition, we found no effect of intertrain interval on the reduction of the amplitude of the second PSP relative to the first (52\% for $1.75 \mathrm{~s}$ intertrain interval vs $45 \%$ for intervals longer than $5 s ; p>0.2$ ). These results suggest that complete recovery from depression required no more than $1.75 \mathrm{~s}$.

In addition to reducing thalamocortical depression, reducing spontaneous LGN activity could have at least two other effects on the cortex. First, a reduction in synaptic activity throughout the cortical circuit could, in theory, increase neuronal input resistance, with a consequent increase in EPSP amplitude. Large changes in input resistance and the resulting increase in time constant could, in turn, lengthen the decay time of the EPSPs. No such changes were observed, however (Fig. 9D). Similarly, in in vitro preparations of cat visual cortex (Stratford et al., 1996; Tarczy-Hornoch et al., 1999; Bannister et al., 2002), in which thalamocortical axons have been severed and are presumably inactive, input resistance values are comparable with those observed in vivo in this and other studies (Pei et al., 1991; BorgGraham et al., 1998; Anderson et al., 2000). Ongoing thalamocortical activity therefore does not seem to generate large reductions in resting conductance.

A second potential intracortical effect of retinal inactivation could be an increase in the excitability of the cortical circuit, through either reduced synaptic depression at corticocortical synapses or a decrease in inactivated $\mathrm{Na}^{+}$-channels in cortical neurons. These mechanisms would only have an effect on later, polysynaptic components of the response to LGN stimulation, whereas retinal inactivation caused a clear increase in the entire response, including its earliest components (Fig. 9D). Thus, our results are consistent with the idea that ongoing activity in the LGN places the thalamocortical synapses in a state of tonic depression.

\section{Models of depression}

In many cases, synaptic depression can be understood as the interaction between two processes, the activity-dependent depletion of the readily releasable pool of synaptic vesicles and the slow replenishment of the pool. The depletion process can be modeled by the parameter $f$, the ratio of the synaptic resources available immediately after release to the resources available immediately before release. This parameter is directly related to $p$, the probability of vesicle release. The replenishment process can be modeled by the parameter $\tau_{\text {rec }}$, the time constant of recovery from depression (Abbott et al., 1997; Tsodyks and Markram, 1997; Kayser et al., 2001).

Fits to paired-pulse data obtained in vitro in cat visual cortex (Stratford et al., 1996) gave values of 0.563 for $f$ and $99 \mathrm{~ms}$ for $\tau_{\text {rec }}$ (Kayser et al., 2001). The time course for depression predicted for a $50 \mathrm{~Hz}$ train from these two values is shown by the dotted gray curve in Figure $9 F$. Because the paired-pulse experiments were performed in vitro in which there is little spontaneous activity in the thalamic afferents, these results are most comparable with our measurements of depression during pressure-induced suppression of LGN activity. The two-parameter curve in Figure 9F, however, does not accurately fit the amplitude of the second through seventh responses in the train. Because of the transient character of the depression observed, the exponential description of paired-pulse depression between the first two PSPs underestimates initial depression and overestimates the amount of depression that occurs later in the train.

\section{Discussion}

We found that repetitive activation of LGN afferents in vivo does not induce profound changes in the level of synaptic depression at the geniculocortical synapse. The peak amplitude of the PSP evoked by electrical stimulation of the LGN decrements little during the course of brief trains of stimuli. Even at $100 \mathrm{~Hz}$, the PSP amplitude never falls below $60 \%$ of its initial value by the third stimulus in the train. At $20 \mathrm{~Hz}$, the PSP never falls to $<80 \%$ of its initial amplitude.

Our results indicate that thalamocortical synaptic depression is likely to be near saturation in the anesthetized animal and, by extension, the awake animal, in which spontaneous firing rates are as high or higher (Weyand, personal communication). Furthermore, we find that decrements in PSP amplitude during trains of stimuli are smaller than those predicted from a singleexponential estimate of paired-pulse depression and may even recover somewhat later in the train. This low level of response suppression constrains the role of thalamocortical depression in the shaping of visual cortical response properties, especially to stimuli of extended duration, such as drifting gratings.

\section{Effects of ongoing activity on short-term synaptic depression}

The relatively modest level of depression that we observed in the response to trains of electrical stimuli does not imply that geniculocortical synapses do not depress under any circumstances. Rather, our data show, as proposed by Sanchez-Vives et al. (1998), that electrical stimulation, and by extension visual stimulation, does not dramatically increase the level of depression beyond what is present at rest. That a resting level of depression is set by the spontaneous activity of the LGN in our preparation is suggested by the retinal inactivation experiments. This effect of spontaneous activity on synaptic efficacy has also been shown in rat somatosensory cortex in vivo, in which increases in background activity associated with sleep-wake cycles, changes in arousal, or stimulation of brainstem activating systems reduce the level of depression observed in field potentials evoked by thalamic stimulation (Castro-Alamancos, 2002; CastroAlamancos and Oldford, 2002). 


\section{Rapidly saturating depression at other synapses}

Rapidly saturating depression, in which a dramatic drop in EPSP amplitude after the first release event is followed by little additional depression, has been described in vitro at both excitatory and inhibitory synapses, including the calyx of Held (Brenowitz and Trussell, 2001), retinogeniculate synapses (Chen et al., 2002), neocortical synapses (Galarreta and Hestrin, 1998), climbing fiber synapses onto cerebellar Purkinje cells (Dittman et al., 2000), inhibitory synapses in the hippocampus (Kraushaar and Jonas, 2000), and cerebellar corticonuclear synapses (Telgkamp and Raman, 2002). In many cases, these synapses have been shown to have morphological and physiological specializations that distinguish them from typical central synapses. No such physiological or anatomical specializations of the thalamocortical synapse in cat visual cortex have been reported, except that this synapse tends to form larger boutons than do other synaptic contacts onto layer IV cells (Ahmed et al., 1994; Kharazia and Weinberg, 1994). In rat barrel cortex, thalamocortical synapses have also been found to have a larger number of release sites (Gil et al., 1999; Amitai, 2001) than other inputs onto layer IV cells.

\section{Comparison with in vitro experiments}

Our measurements of the decrement between the first and second EPSPs during LGN inactivation are in relatively good agreement with in vitro measurements of paired-pulse depression (Stratford et al., 1996; Bannister et al., 2002). The difference between the in vitro results and our measurements made with physiological levels of spontaneous activity most likely stems from the spontaneous activity itself. There are other differences in the two preparations, however, that should be noted. (1) In the in vitro experiments, NMDA components of the EPSPs were blocked. (2) Neuromodulators present in vivo may affect thalamocortical synaptic transmission (Gil et al., 1997; Sanchez-Vives et al., 1999; Hsieh et al., 2000; Oldford and Castro-Alamancos, 2003). For example, neuromodulators likely contribute to the differences in synaptic depression observed in vivo (Usrey et al., 1998; Rowe and Fischer, 2001) and in vitro at the retinogeniculate synapse (Chen and Regehr, 2003). (3) Electrical stimulation of the LGN likely evoked spikes in more than one relay cell. Previous results, however, suggest that activation of multiple inputs would not affect our estimates of synaptic depression (Usrey et al., 2000). (4) Stimulation of the LGN in vivo evoked strong disynaptic inhibition, unlike the minimal stimulation protocol used in vitro. (5) Our animals were older than those used in the in vitro studies, and depression in thalamocortical synapses may be developmentally regulated, as has been found for neocortical synapses (Reyes and Sakmann, 1999). (6) The extracellular $\mathrm{Ca}^{2+}$ concentration used in the in vitro experiments was higher than that present in vivo, possibly leading to higher probability of release and greater depression. (7) The circuitry of the LGN is intact in our experiments. Local inhibition evoked by stimulation of the LGN could elevate relay cell thresholds for stimuli later in the train. Additionally, this inhibition could itself be subject to short-term synaptic depression, which would contribute to the slight recovery of the responses in monosynaptic cells seen later in our trains.

\section{Depression at corticocortical synapses}

Experiments in vitro show a variety of behaviors at different corticocortical synapses (Finlayson and Cynader, 1995; TarczyHornoch et al., 1998, 1999; Yoshimura et al., 2000). Our experiments cannot assess depression at corticocortical synapses directly. In those neurons that did not receive direct input from the LGN (polysynaptic cells), responses fell significantly after a single shock to the LGN. The origin of the near failure of the second and subsequent responses in the train could be depression at the corticocortical synapse, shunting of the polysynaptic cells, or action potential failure in the presynaptic cortical neurons that mediate the EPSP. We suspect that the latter two occur at least to some degree. In both monosynaptic and polysynaptic cortical cells, the first LGN shock elicits long-lasting inhibition that likely reduces excitability, similar to the effects of cortical stimulation (Chung and Ferster, 1998; Kara et al., 2002). In support of this interpretation, both a cortical shock and the first LGN shock dramatically reduce the amplitude of subsequent EPSPs in polysynaptic cells (Figs. 5, 6). The same considerations apply to inhibitory corticocortical connections. As shown in Figure 7, C and $F$, inhibitory conductance, like polysynaptic excitatory conductance, falls to a small fraction of its initial amplitude after a single shock to the LGN or to the cortex. Here again, this reduction could represent synaptic depression, shunting, or a failure of the interneurons to fire. It is known that, in rat auditory cortex (Metherate and Ashe, 1994) and somatosensory cortex (Pinto et al., 2003), intracortical inhibition plays a crucial role in damping responses to high-frequency sensory stimulation.

\section{Thalamocortical depression in other sensory systems}

In the rodent somatosensory cortex, in which thalamocortical synaptic depression is most studied, in vitro experiments show some depression at $10 \mathrm{~Hz}$ (Gil et al., 1997) and stronger depression at higher frequencies $(20-40 \mathrm{~Hz}$ ) (Gibson et al., 1999; Gil et al., 1999). In anesthetized animals in vivo, $4 \mathrm{~Hz}$ whisker stimulation, which can evoke thalamic spike rates of $10-30 \mathrm{~Hz}$, caused strong depression in somatosensory cortical EPSPs (Chung et al., 2002). Electrical stimulation of the thalamic radiation at $10 \mathrm{~Hz}$ produced significant depression in field potentials (CastroAlamancos and Oldford, 2002). In the awake rabbit, thalamic relay cell spikes have higher efficacy when preceded by periods of silence (Swadlow and Gusev, 2001), suggesting that spontaneous firing maintains a partially depressed state. In the rodent visual system, there is substantial paired-pulse depression of cortical field potentials evoked by $10 \mathrm{~Hz}$ stimulation of the LGN (Jia et al., 2004). The field potential effects, however, may be attributable to short-term plasticity at second-order synapses as well as at the thalamocortical synapse. Hellweg et al. (1977) recorded intracellularly in vivo from the cortical whisker projection areas $(8,9$, and 17) and showed that subthreshold responses could follow stimulation of the infraorbital nerve with high fidelity at $50 \mathrm{~Hz}$. Many of the differences in the amount of response suppression observed in these different preparations may stem from variability in the age of the animals and in the anesthesia used or differences between sensory modalities or species.

\section{Consequences for cortical neurons}

The fast, nonexponential depression we have observed at the thalamocortical synapse implies that increases in thalamic activity above background rates do not induce large increases in synaptic depression. As a result, stimulus-evoked LGN spikes are likely transmitted to cortical neurons faithfully, even at high firing rates. We have not investigated synaptic depression during extremely long trains of spikes, which might be evoked by longlasting and intense visual stimulation, nor have we studied the depression that might occur during burst firing of geniculate relay cells (Sherman, 2001). Still, our findings show that, for stimuli approximating physiological LGN firing rates, thalamically driven EPSPs remain robust during repeated stimulation. 


\section{References}

Abbott LF, Varela JA, Sen K, Nelson SB (1997) Synaptic depression and cortical gain control. Science 275:220-224.

Adelson EH, Bergen JR (1985) Spatiotemporal energy models for the perception of motion. J Opt Soc Am A 2:284-299.

Ahmed B, Anderson JC, Douglas RJ, Martin KA, Nelson JC (1994) Polyneuronal innervation of spiny stellate neurons in cat visual cortex. J Comp Neurol 341:39-49.

Ainsworth A, Dostrovsky JO, Merrill EG, Millar J (1977) An improved method for insulating tungsten micro-electrodes with glass [proceedings]. J Physiol (Lond) 269:4P-5P.

Amitai Y (2001) Thalamocortical synaptic connections: efficacy, modulation, inhibition and plasticity. Rev Neurosci 12:159-173.

Anderson JS, Carandini M, Ferster D (2000) Orientation tuning of input conductance, excitation, and inhibition in cat primary visual cortex. J Neurophysiol 84:909-926.

Bannister NJ, Nelson JC, Jack JJ (2002) Excitatory inputs to spiny cells in layers 4 and 6 of cat striate cortex. Philos Trans R Soc Lond B Biol Sci 357:1793-1808.

Beierlein M, Connors BW (2002) Short-term dynamics of thalamocortical and intracortical synapses onto layer 6 neurons in neocortex. J Neurophysiol 88:1924-1932.

Borg-Graham LJ, Monier C, Fregnac Y (1998) Visual input evokes transient and strong shunting inhibition in visual cortical neurons. Nature 393:369-373.

Brenowitz S, Trussell LO (2001) Minimizing synaptic depression by control of release probability. J Neurosci 21:1857-1867.

Buchs NJ, Senn W (2002) Spike-based synaptic plasticity and the emergence of direction selective simple cells: simulation results. J Comput Neurosci 13:167-186.

Carandini M, Ferster D (1997) A tonic hyperpolarization underlying contrast adaptation in cat visual cortex. Science 276:949-952.

Carandini M, Ferster D (2000) Membrane potential and firing rate in cat primary visual cortex. J Neurosci 20:470-484.

Carandini M, Heeger DJ, Senn W (2002) A synaptic explanation of suppression in visual cortex. J Neurosci 22:10053-10065.

Castro-Alamancos MA (2002) Different temporal processing of sensory inputs in the rat thalamus during quiescent and information processing states in vivo. J Physiol (Lond) 539:567-578.

Castro-Alamancos MA (2004) Absence of rapid sensory adaptation in neocortex during information processing states. Neuron 41:455-464.

Castro-Alamancos MA, Oldford E (2002) Cortical sensory suppression during arousal is due to the activity-dependent depression of thalamocortical synapses. J Physiol (Lond) 541:319-331.

Chance FS, Nelson SB, Abbott LF (1998) Synaptic depression and the temporal response characteristics of v1 cells. J Neurosci 18:4785-4799.

Chen C, Regehr WG (2003) Presynaptic modulation of the retinogeniculate synapse. J Neurosci 23:3130-3135.

Chen C, Blitz DM, Regehr WG (2002) Contributions of receptor desensitization and saturation to plasticity at the retinogeniculate synapse. Neuron 33:779-788.

Chung S, Ferster D (1998) Strength and orientation tuning of the thalamic input to simple cells revealed by electrically evoked cortical suppression. Neuron 20:1177-1189.

Chung S, Li X, Nelson SB (2002) Short-term depression at thalamocortical synapses contributes to rapid adaptation of cortical sensory responses in vivo. Neuron 34:437-446.

Dean AF, Tolhurst DJ (1986) Factors influencing the temporal phase of response to bar and grating stimuli for simple cells in the cat striate cortex. Exp Brain Res 62:143-151.

Dittman JS, Kreitzer AC, Regehr WG (2000) Interplay between facilitation, depression, and residual calcium at three presynaptic terminals. J Neurosci 20:1374-1385.

Douglas RJ, Martin KA (1991) A functional microcircuit for cat visual cortex. J Physiol (Lond) 440:735-769.

Efron B, Tibshirani RJ (1993) An introduction to the bootstrap. New York: Chapman and Hall.

Ernest JT, Potts AM (1969) Pathophysiology of the distal portion of the optic nerve. 3. Effect of intraocular pressure on optic nerve discharge. Am J Ophthalmol 68:594-604.

Ferster D, Lindström S (1983) An intracellular analysis of geniculo-cortical connectivity in area 17 of the cat. J Physiol (Lond) 342:181-215.
Ferster D, Lindström S (1985) Augmenting responses evoked in area 17 of the cat by intracortical axon collaterals of cortico-geniculate cells. J Physiol (Lond) 367:217-232.

Finlayson PG, Cynader MS (1995) Synaptic depression in visual cortex tissue slices: an in vitro model for cortical neuron adaptation. Exp Brain Res 106:145-155.

Freeman TC, Durand S, Kiper DC, Carandini M (2002) Suppression without inhibition in visual cortex. Neuron 35:759-771.

Galarreta M, Hestrin S (1998) Frequency-dependent synaptic depression and the balance of excitation and inhibition in the neocortex. Nat Neurosci 1:587-594.

Gibson JR, Beierlein M, Connors BW (1999) Two networks of electrically coupled inhibitory neurons in neocortex. Nature 402:75-79.

Gil Z, Connors BW, Amitai Y (1997) Differential regulation of neocortical synapses by neuromodulators and activity. Neuron 19:679-686.

Gil Z, Connors BW, Amitai Y (1999) Efficacy of thalamocortical and intracortical synaptic connections: quanta, innervation, and reliability. Neuron 23:385-397.

Hellweg FC, Schultz W, Creutzfeldt OD (1977) Extracellular and intracellular recordings from cat's cortical whisker projection area: thalamocortical response transformation. J Neurophysiol 40:463-479.

Horsten GP, Winkelman JE (1957) Relationship between intraocular pressure, blood pressure and electroretinogram. Acta Physiol Pharmacol Neerl 6:586-596.

Hsieh CY, Cruikshank SJ, Metherate R (2000) Differential modulation of auditory thalamocortical and intracortical synaptic transmission by cholinergic agonist. Brain Res 880:51-64.

Jia F, Xie X, Zhou Y (2004) Short-term depression of synaptic transmission from rat lateral geniculate nucleus to primary visual cortex in vivo. Brain Res 1002:158-161.

Kara P, Pezaris JS, Yurgenson S, Reid RC (2002) The spatial receptive field of thalamic inputs to single cortical simple cells revealed by the interaction of visual and electrical stimulation. Proc Natl Acad Sci USA 99:16261-16266.

Kayser A, Priebe NJ, Miller KD (2001) Contrast-dependent nonlinearities arise locally in a model of contrast-invariant orientation tuning. J Neurophysiol 85:2130-2149.

Kharazia VN, Weinberg RJ (1994) Glutamate in thalamic fibers terminating in layer IV of primary sensory cortex. J Neurosci 14:6021-6032.

Kraushaar U, Jonas P (2000) Efficacy and stability of quantal GABA release at a hippocampal interneuron-principal neuron synapse. J Neurosci 20:5594-5607.

Lauritzen TZ, Krukowski AE, Miller KD (2001) Local correlation-based circuitry can account for responses to multi-grating stimuli in a model of cat V1. J Neurophysiol 86:1803-1815.

Metherate R, Ashe JH (1994) Facilitation of an NMDA receptor-mediated EPSP by paired-pulse stimulation in rat neocortex via depression of GABAergic IPSPs. J Physiol (Lond) 481:331-348.

Muller JR, Metha AB, Krauskopf J, Lennie P (1999) Rapid adaptation in visual cortex to the structure of images. Science 285:1405-1408.

Nelson SB (1991a) Temporal interactions in the cat visual system. I. Orientation-selective suppression in the visual cortex. J Neurosci 11:344-356.

Nelson SB (1991b) Temporal interactions in the cat visual system. II. Suppressive and facilitatory effects in the lateral geniculate nucleus. J Neurosci 11:357-368.

Nelson SB (1991c) Temporal interactions in the cat visual system. III. Pharmacological studies of cortical suppression suggest a presynaptic mechanism. J Neurosci 11:369-380.

Oldford E, Castro-Alamancos MA (2003) Input-specific effects of acetylcholine on sensory and intracortical evoked responses in the "barrel cortex" in vivo. Neuroscience 117:769-778.

Ozeki H, Sadakane O, Akasaki T, Naito T, Shimegi S, Sato H (2004) Relationship between excitation and inhibition underlying size tuning and contextual response modulation in the cat primary visual cortex. J Neurosci 24:1428-1438.

Pei X, Volgushev M, Vidyasagar TR, Creutzfeldt OD (1991) Whole cell recording and conductance measurements in cat visual cortex in-vivo. NeuroReport 2:485-488.

Pinto DJ, Hartings JA, Brumberg JC, Simons DJ (2003) Cortical damping: analysis of thalamocortical response transformations in rodent barrel cortex. Cereb Cortex 13:33-44. 
Priebe NJ, Ferster D (2005) Direction selectivity of excitation and inhibition in simple cells of the cat primary visual cortex. Neuron 45:133-145.

Reid RC, Soodak RE, Shapley RM (1991) Directional selectivity and spatiotemporal structure of receptive fields of simple cells in cat striate cortex. J Neurophysiol 66:505-529.

Reyes A, Sakmann B (1999) Developmental switch in the short-term modification of unitary EPSPs evoked in layer 2/3 and layer 5 pyramidal neurons of rat neocortex. J Neurosci 19:3827-3835.

Rowe MH, Fischer Q (2001) Dynamic properties of retino-geniculate synapses in the cat. Vis Neurosci 18:219-231.

Sanchez-Vives MV, Nowak LG, McCormick DA (1998) Is synaptic depression prevalent in vivo and does it contribute to contrast adaptation? Soc Neurosci Abst 24:354.15.

Sanchez-Vives MV, Nowak LG, McCormick DA (1999) Why might synaptic depression be lesser in vivo than in vitro? Soc Neurosci Abst 25:874.10.

Sanchez-Vives MV, Nowak LG, McCormick DA (2000) Membrane mechanisms underlying contrast adaptation in cat area 17 in vivo. J Neurosci 20:4267-4285.

Sherman SM (2001) Tonic and burst firing: dual modes of thalamocortical relay. Trends Neurosci 24:122-126.

Shu Y, Hasenstaub A, McCormick DA (2003) Turning on and off recurrent balanced cortical activity. Nature 423:288-293.

Stratford KJ, Tarczy-Hornoch K, Martin KA, Bannister NJ, Jack JJ (1996) Excitatory synaptic inputs to spiny stellate cells in cat visual cortex. Nature 382:258-261.

Swadlow HA, Gusev AG (2001) The impact of 'bursting' thalamic impulses at a neocortical synapse. Nat Neurosci 4:402-408.
Swadlow HA, Gusev AG, Bezdudnaya T (2002) Activation of a cortical column by a thalamocortical impulse. J Neurosci 22:7766-7773.

Takeda Y, Nakai Y, Takaori S (1972) Analysis of evoked responses in the visual pathway of cats with elevation of the intraocular pressure. Brain Res 43:373-381.

Tarczy-Hornoch K, Martin KA, Jack JJ, Stratford KJ (1998) Synaptic interactions between smooth and spiny neurones in layer 4 of cat visual cortex in vitro. J Physiol (Lond) 508:351-363.

Tarczy-Hornoch K, Martin KA, Stratford KJ, Jack JJ (1999) Intracortical excitation of spiny neurons in layer 4 of cat striate cortex in vitro. Cereb Cortex 9:833-843.

Telgkamp P, Raman IM (2002) Depression of inhibitory synaptic transmission between Purkinje cells and neurons of the cerebellar nuclei. J Neurosci 22:8447-8457.

Tsodyks MV, Markram H (1997) The neural code between neocortical pyramidal neurons depends on neurotransmitter release probability. Proc Natl Acad Sci USA 94:719-723.

Usrey WM, Reppas JB, Reid RC (1998) Paired-spike interactions and synaptic efficacy of retinal inputs to the thalamus. Nature 395:384-387.

Usrey WM, Alonso J-M, Reid RC (2000) Synaptic interactions between thalamic inputs to simple cells in cat visual cortex. J Neurosci 20:5461-5467.

Volgushev M, Pernberg J, Eysel UT (2002) A novel mechanism of response selectivity of neurons in cat visual cortex. J Physiol (Lond) 540:307-320.

Yoshimura Y, Sato H, Imamura K, Watanabe Y (2000) Properties of horizontal and vertical inputs to pyramidal cells in the superficial layers of the cat visual cortex. J Neurosci 20:1931-1940. 